\title{
Analytical modeling of tube-to-tubesheet joints subjected to plastic deformation and creep
}

\author{
Abdel-Hakim BOUZID * and Nor-Eddine LAGHZALE ** \\ * Department of Mechanical Engineering, Ecole de Technologie Superieure \\ 1100 Rue Notre-Dame O, Montréal, Canada \\ E-mail: hakim.bouzid@etsmtl.ca \\ **Université Mohamed 5 Suissi \\ Angle avenue Allal El Fassi et Mfadel Cherkaoui, Rabat, Maroc
}

Received 28 November 2015

\begin{abstract}
The mechanism of failure of heat exchanger and steam generator tube-to-tubesheet joints is related to the level of residual stresses produced in the tube expansion and transition zones during the expansion process and their variation during operation. The accurate prediction of these stresses based on the plastic and creep properties of the joint materials involved can help to design for better leak tightness and strength. Existing design calculations are based on an elastic perfectly plastic behavior of the expansion joint materials and do not account for creep. The proposed model is based on a linear strain hardening material behavior and considers the joint contact pressure relaxation with time. The interaction of the tube and the tubesheet is simulated during the process of the application of the expansion pressure and operation. The effects of the gap, material strain hardening and creep properties are to be emphasized. The developed model results are validated and confronted against the more accurate numerical FEA models.
\end{abstract}

Key words : Tube-to-tubesheet joint, Creep-relaxation, Analytical model, FE model, Hydraulic expansion, Residual contact stress

\section{Introduction}

Steam generators and heat exchanger are used to transfer heat from one fluid to the other. This is achieved by a shell and tubes configuration which employ expanded tube-to-tubesheet joints. Several causes can be at the origin of leak in this equipment. Cracks due to intergranular attack, corrosion under stress or fatigue in the joint transition zone are to name a few. However, the loss of the initial residual contact pressure due to insufficient initial expansion or relaxation may be the source of a leak at the tube-to-tubesheet joint interface, causing a mixing between the two fluids.

The interface residual stress and its relaxation with time are not adequately covered by a detailed standardized design procedure. Existing standards such as TEMA (TEMA, 1999) give only limited information. They do not provide a design methodology to follow in order to insure a desired structural integrity and leak tightness after the expansion process and during the life time of expanded joints (Sang et al., 1996). The expansion of tube-to-tubesheet joints has been the subject of both analytical and experimental studies. Several researchers have developed analytical models (Goodier and Schoessow, 1943) and proposed equations that give the residual contact pressure, (Krips and Podhorsky, 1976, Yokell, 1992, Kohlpaintner, 1995). However few studies that treat failures in transition zones were conducted (Grimison and Lee, 1943, Cizelj and Mavko, 1993). In parallel, experimental investigations were conducted to mainly evaluate the strength of the tube-to-tube sheet adhesion and tightness by performing push-pull tests (Shuaib et al., 2001, Allam M. and Bazergui, 2002). Middlebrook et al., 1993 showed that the relaxation effects on the residual contact pressure are not significant if the service temperature remains below $482{ }^{\circ} \mathrm{C}$.

This paper deals with the analytical solution for the contact pressure when strain hardening of both the tube and tubesheet are present. The relaxation of this contact stress is also modeled. The effect of strain hardening and clearance on this contact pressure and its variation during operation are also studied. The developed models are validated using the more accurate FEA. 


\section{Theoretical analysis of hydraulic expansion}

Two assumptions are made. The model is simplified by considering one tube with a small region of tubesheet that includes part of the ligament and assumed to behave like a thick cylinder with an equivalent thickness based on the work by Chabaan et al. 1992. Therefore if the tubesheet has a square or triangular pattern, only a small region around one hole is considered using the equivalent cylinder external radius concept as shown in Fig. 1 by radius $R_{o}$. Both the tube and the tubesheet shown in Fig. 1 are considered as thick cylinders. The second assumption is that the whole tube section undergoes fully plastic deformation before it touches the wall of the tubesheet. This presumes that, immediately

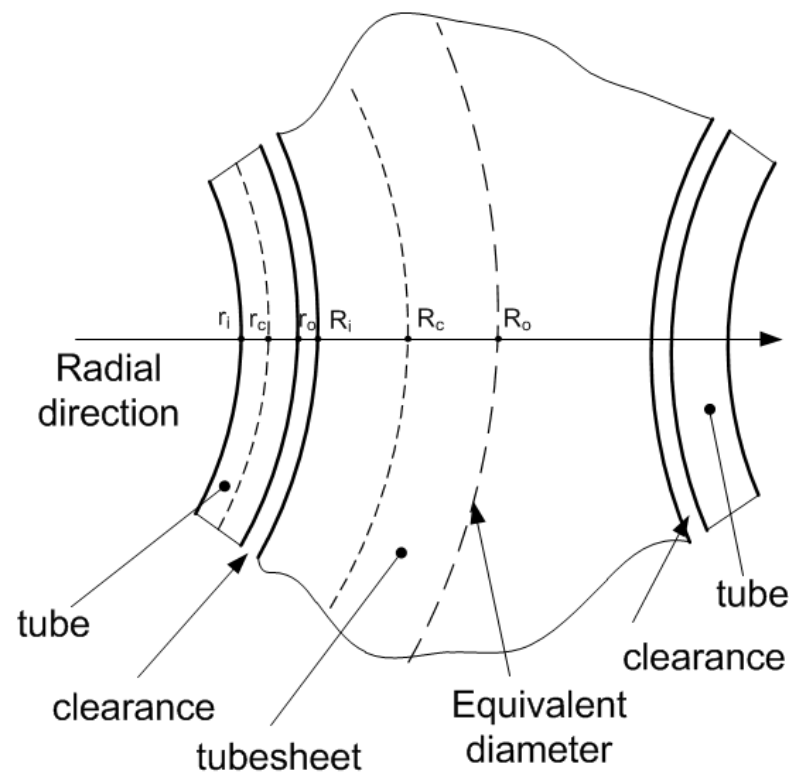

Fig. 1 Tube-to-tubesheet geometry

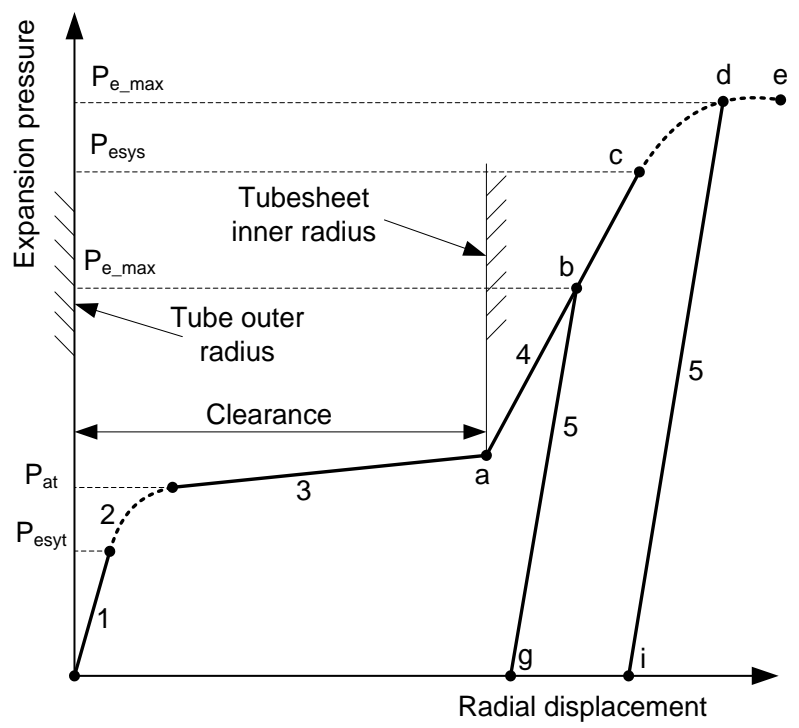

Fig. 2 expansion pressure sequence

after fully plastic deformation, the displacement of tube outer surface remains lower than the initial clearance. In practice, initial clearances are much higher than the fully plastic displacement; the recommended clearances are given by TEMA.

According to the maximum level of the expansion pressure, the geometry and mechanical characteristics of the joint, two cases are distinguished:

1- case of expansion without plastic deformation of the tubesheet (Fig. 2 steps 1-2-3-4-ab-5-g).

2- case of expansion with plastic deformation of the tubesheet during the loading phase (Fig. 2 steps 1-2-3-4-acd-5-di).

The case of reverse yielding of the tube and tubesheet during the unloading phase is not treated in this paper. In order to validate the analytical model, simulations were run using a general purpose finite element program with different cases. Results from existing models were also compared and commented on in this paper.

\subsection{Residual contact pressure}

\subsubsection{Allam's approach}

Apart from the finite element analyses, very few analytical investigations looking into the effect of strain hardening were carried out in the field of expanded joints. In 1998, based on Tresca criteria, Allam et al. formulated the equation below which gives the expression of the residual contact pressure:

$$
P_{c}^{*}=\bar{f} \frac{\alpha_{1}}{K}\left(P_{e_{-} \max }-\alpha_{2} P_{e_{-} \min }\right)
$$

$P_{c}{ }^{*}, P_{e_{-} \max }$ and $P_{e_{-} \min }$ indicate, respectively, the residual contact pressure, the maximum expansion pressure and the minimal expansion pressure which closes the initial clearance without residual contact pressure. $K$ is a coefficient 
which takes account of the geometrical and joint mechanical characteristics.

$$
K=1+\frac{E_{s}}{E_{t}} \frac{1}{\left(1+c / 2 r_{o}\right)} \frac{\left(Y_{t}^{2}-1\right)}{\left(Y_{s}^{2}-1\right)}\left[\frac{1+v_{t}+\left(1-v_{t}\right) Y_{t}^{2}}{1-v_{s}+\left(1+v_{s}\right) Y_{s}^{2}}\right]
$$

And

$$
p_{\mathrm{e}_{-} \min }=\frac{E_{s}}{E_{t}} \frac{2 S_{y t}}{\left(1+c / 2 r_{o}\right)} \frac{\left(Y_{t}^{2}-1\right)}{\left(Y_{s}^{2}-1\right)}\left[\frac{\ln Y_{t}}{1-v_{s}+\left(1+v_{s}\right) Y_{s}^{2}}\right]+S_{y t} \ln Y_{t}
$$

$\alpha_{1}$ and $\alpha_{2}$ are two coefficients estimated from finite element modelling to be 1.15 and 0.85 respectively in order to adjust their model to account for Von Mises criteria. A coefficient $\bar{f}$ was also introduced in Eq. (1) to account for strain hardening of the tube. Its expression is given by:

$$
\bar{f}=0.91745-5559.02128\left(\frac{C}{2 r_{o}}\right)\left(\frac{E_{t t}}{E_{t}}\right)-1.48397\left(\frac{E_{t t}}{E_{t}}\right)
$$

\subsubsection{Current developed model}

\section{Expansion without tubesheet plastic deformation}

The material behaviour of the tube is considered to be bilinear. Although the elastic perfectly plastic behaviour treated previously (Laghzale and Bouzid, 2009a) is not suitable for this study, other more realistic plasticity laws, like those developed by Ramberg and Osgood, 1943 can also be applied. However, with such laws, the implementations of the equations which govern the expansion process are generally more complex and a linear hardening behaviour proves to be more adapted to our analysis. In order to further simplify the analysis, the grooves, the seal welding and the transition zones are not considered.

During the phase of loading, the maximum expansion pressure $P_{e_{-} \max }$ is supposed to be lower than the pressure $P_{\text {esys }}$ at which yield of the tubesheet occurs at the end of the loading phase. If the expansion pressure $P_{e}$ being at its maximum value $P_{e_{-} \text {max }}$, any pressure decrease beyond this value involves the simultaneous elastic recovery of the tube and the tubesheet. The contact pressure is obtained by analyzing the change in the radial displacement at their interface of the tube and tubesheet both treated as thick cylinders subjected to elasto-plastic deformation with linear strain hardening (Laghzale and Bouzid, 2009b). The change of displacement during the release of expansion pressure must be the same such that:

$$
\Delta U_{r}^{t}\left(r_{o}\right)=\Delta U_{r}^{s}\left(R_{i}\right)
$$

During unloading, the tube relative radial displacement is given by the elastic recovery from the state where it is subjected to maximal internal and external pressures $P_{e_{-} \max }$ and $P_{c_{-} \max }$ to a lower state level of internal and external pressures $P_{e}$ and $P_{c}$ such that:

$$
\Delta U_{r}^{t}\left(r_{o}\right)=\frac{r_{o}\left(1+v_{t}\right)}{E_{t}\left(Y_{t}^{2}-1\right)}\left\{2\left(1-v_{t}\right)\left(P_{e}-P_{e_{-} \max }\right)-\left(P_{c}-P_{c_{-} \max }\right)\left[1+Y_{t}^{2}\left(1-2 v_{t}\right)\right]\right\}
$$

Where $P_{a t}$ is the tube autofrettaged pressure and $P_{c_{-} \max }$ is the contact pressure at the maximum expansion pressure the expression of which are:

$$
\begin{gathered}
P_{a t}=\frac{S_{y t}}{\sqrt{3}} \frac{A_{t} \cdot E_{p t}\left(Y_{t}^{2}-1\right)+2 \ln \left(Y_{t}\right)}{1+A_{t} \cdot E_{p t}} \\
P_{c_{-} \max }=\frac{1}{\gamma}\left\{\frac{E_{t t}}{r_{o}}\left(Y_{t}^{2}-1\right)\left(\frac{2 r_{o}}{\sqrt{3}} \frac{S_{y t}\left(1-v_{t}^{2}\right)}{E_{t}}-C\right)+2\left(1-\bar{v}^{2}\right)\left(P_{e_{-} \max }-P_{a t}\right)\right\}
\end{gathered}
$$


And

$$
\begin{gathered}
A_{t}=\frac{2\left(2-v_{t}^{2}\right)}{3 E_{t}} \\
\gamma=(1+\bar{v})\left[1+(1-2 \bar{v}) Y_{t}^{2}\right]+\frac{E_{t t}\left(Y_{t}^{2}-1\right)}{E_{s}\left(Y_{s}^{2}-1\right)}\left(1+v_{s}\right)\left(1+Y_{s}^{2}-2 v_{s}\right)
\end{gathered}
$$

The tubesheet relative radial displacement at the inner radius $R_{i}$ (and noting that $R_{i}=r_{o}$ ) is given by the elastic recovery from the state where it is subjected to maximal internal contact pressures $P_{c_{-} \max }$ to the lower state level of internal pressure $P_{c}$ such that:

$$
\Delta U_{r}^{s}\left(R_{i}\right)=\frac{R_{i}\left(1+v_{s}\right)}{E_{s}\left(Y_{s}^{2}-1\right)}\left(P_{c}-P_{c_{-} \max }\right)\left(1-2 v_{s}+Y_{s}^{2}\right)
$$

Substituting Eqs. (6) and (9) into Eq. (5), gives the contact pressure during the unloading of the expansion process:

$$
P_{c}=P_{c_{-} \max }+\lambda\left(P_{e}-P_{e_{-} \max }\right)
$$

Where $\lambda$ is given by:

$$
\lambda=\frac{2\left(1-v_{t}^{2}\right)}{\frac{E_{t}\left(Y_{t}^{2}-1\right)}{E_{s}\left(Y_{s}^{2}-1\right)}\left(Y_{s}^{2}+1-2 v_{s}\right)\left(1+v_{s}\right)+\left(1+v_{t}\right)\left[1+Y_{t}^{2}\left(1-2 v_{t}\right)\right]}
$$

The residual contact pressure $P_{c}{ }^{*}$ is given by putting the expansion pressure $P_{e}$ equal to zero in Eq. (9) such that:

$$
P_{c}^{*}=P_{c_{-} \max }-\lambda P_{e_{-} \max }
$$

\section{Expansion with tubesheet elasto-plastic deformation}

The unloading phase is treated similarly as the unloading without tubesheet yielding. Equations (9) to (11) remain applicable with $P_{c_{-} \max }$ given by:

$$
P_{c_{-} \max }=\frac{S_{y s}}{\sqrt{3}}\left\{1-\frac{c_{s_{-} \max }^{2}}{R_{o}^{2}}+\frac{A_{s} E_{p s}\left(\frac{c_{s_{-} \max }^{2}}{R_{i}^{2}}-1\right)+2 \ln \left(\frac{c_{s_{-} \max }}{R_{i}}\right)}{1+A_{s} E_{p s}}\right\}
$$

Where $A_{s}=2\left(2-v_{s}\right) / 3 E_{s}$ and at the end of loading phase, the calculation of $P_{c_{-} \text {max }}$ is conditioned by the determination of the elastic plastic tubesheet radius $c_{s_{-} \max }$. When $P_{e}=P_{e_{-} \max }$, the tube and tubesheet radial displacement at the inner radius $R_{i}$ (and noting that $R_{i}=r_{o}$ ) are given by

$$
\begin{gathered}
\left.U_{r}^{t}\left(r_{o}\right)\right|_{P_{e}=P_{e_{-} \max }}=\left.U_{r}^{t}\left(r_{o}\right)\right|_{P_{a t}}+\frac{r_{o}(1+\bar{v})}{E_{t t}\left(Y_{t}^{2}-1\right)}\left\{2(1-\bar{v})\left(P_{e_{-} \max }-P_{a t}\right)-P_{c_{-} \max }\left[(1-2 \bar{v}) Y_{t}^{2}+1\right]\right\} \\
\left.U_{r}^{s}\left(R_{i}\right)\right|_{P_{e}=P_{e_{-} \max }}=\frac{\left(1+v_{s}\right) S_{y s} R_{i}}{E_{s} \sqrt{3}}\left\{\frac{c_{s_{-} \max }^{2}}{R_{o}^{2}}\left(1-2 v_{s}\right)+1+\frac{1}{1+A_{s} \cdot E_{p s}} .\right. \\
\left.\left[A_{s} \cdot E_{p s}\left(\frac{c_{s_{-} \max }^{2}}{R_{i}^{2}}-1\right)\left(1+\frac{3}{2} \frac{E_{s}}{E_{p s}\left(1+v_{s}\right)}\right)-2 \ln \left(\frac{c_{s_{-} \max }}{R_{i}}\right)\left(1-2 v_{s}\right)\right]\right\}
\end{gathered}
$$

The geometrical compatibility equation is given by:

$$
\left.U_{r}^{t}\left(r_{o}\right)\right|_{P_{e_{-} \max }}=C+\left.U_{r}^{s}\left(R_{i}\right)\right|_{P_{e_{-} \max }}
$$


Substituting Eqs.(14) and (15) into Eq.(16) and replacing $P_{c_{-} \max }$ by its expression in Eq.(13) can result in an equation in $c_{s_{-} \max }$ as a function of $P_{e}=P_{e_{-} \max }$. The geometrical and mechanical characteristics of the joint are shown in Table 1 . The first case corresponds to the case where the tubesheet is not deformed plastically and the second case corresponds to the case of an expansion with partial yielding of the tubesheet. No reverse yielding was considered in these examples.

\subsection{FE model}

Isoparametric plane strain elements with eight nodes were used to model the tube and the tubesheet. Special contact elements were also employed to model the contact surfaces of the tube and the tubesheet. Although a small angle portion could have been used to model the expanded joint, a 90 degree portion was model for simplicity. In order to overcome the problem of the divergence related to the nonlinearity during the loading phase, the expansion pressure was gradually applied, and in particular, when the tube plastic collapse is reached. The plane model is presented, in Fig 3. The friction was not taken into account as previous studies showed that the influence of friction on the residual contact pressure is not significant (Merah et al., 2003). A mesh convergence criterion was run to validate the FE model. In fact, the meshing was refined until the change in the contact pressure was less than $1 \%$. The other parameters such as the stresses and displacements have been found relatively less sensitive to mesh refinement. The characteristics given in Table 1 were used for the analytical and finite elements simulations.

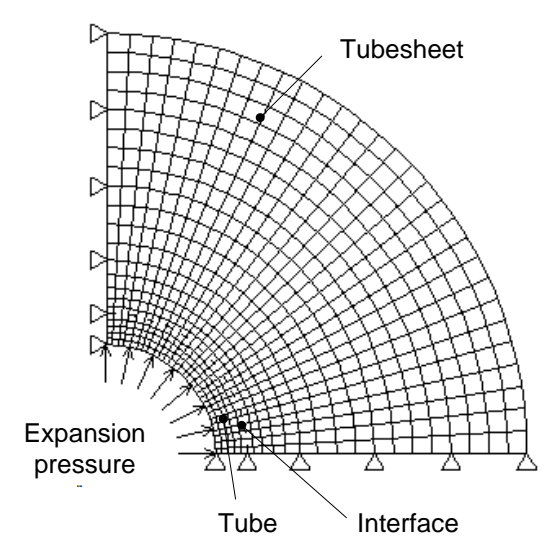

Fig. 3 Plane strain FE models
Table 1 Geometry and material properties

\begin{tabular}{c|c|c|c|c}
\hline \hline & \multicolumn{2}{|c|}{ Case 1 } & \multicolumn{2}{c}{ Case 2 } \\
\cline { 2 - 5 } & Tube & Tubesheet & Tube & Tubesheet \\
\hline$r_{o}, R_{o}[\mathrm{~mm}]$ & 9.5 & 36 & 9.5 & 36 \\
$r_{i}, R_{i}[\mathrm{~mm}]$ & 7.3 & 9.5508 & 7.3 & 9.535 \\
$E_{t}, E_{s}[\mathrm{GPa}]$ & 207 & 207 & 207 & 207 \\
$E_{t t}, E_{t s}[\mathrm{GPa}]$ & 6 & 6 & 6 & 3 \\
$S_{y t}, S_{y s}[\mathrm{MPa}]$ & 248 & 400 & 248 & 180 \\
$v_{t}, v_{s}$ & 0.3 & 0.3 & 0.3 & 0.3 \\
\cline { 2 - 5 }$P_{e_{-} \max }[\mathrm{MPa}]$ & \multicolumn{2}{|c}{270} & \multicolumn{2}{c}{273} \\
$C_{C}[\mathrm{~mm}]$ & 0.0508 & \multicolumn{2}{c}{0.035} \\
\hline
\end{tabular}

\subsection{Results and analysis of hydraulic expansion}

The validity of the developed analytical model is of prime concern before investigating any effect of strain hardening or clearance. This was achieved by a comparison of stresses and displacements at different stages of the expansion on the two cases 1 and 2 of table 1 . Figure 4 gives the radial stress for case 1 where the tubesheet deformation remains elastic. The results between the proposed analytical model and the FEA are in a very good agreement. Referring to Fig. 4, it is worth noting that the radial stress at the tube OD is equal to the radial stress of the tubesheet ID and represents also the contact pressure. At the end of the expansion process, the analytical solution gives a residual contact pressure of 24.6 MPa as compared to 23.9 MPa with FEA while Eq. (1) gives $15.6 \mathrm{MPa}$. The percentage difference with respect to FEM is $3 \%$ for the analytical model while it is $35 \%$ with Eq.(1). Figure 5 shows the results of case 2 which includes partial yielding of the tubesheet. The nonlinear behaviour of the expansion pressure versus displacement just before it reaches its maximum value also confirms this finding as shown in Fig. 5.

The slope of the pressure line representing the rigidity of the structure decreases as plasticity makes its way through the thickness of the tubesheet as in the case of the tube, noting that it becomes constant if fully plastic deformation through the thickness is reached. In case 2, the analytical model predicts $22.04 \%$ plastic zone while FEA gives $22.64 \%$. In addition, the radial stress obtained from the developed theory compares well with that of FEA. At the 


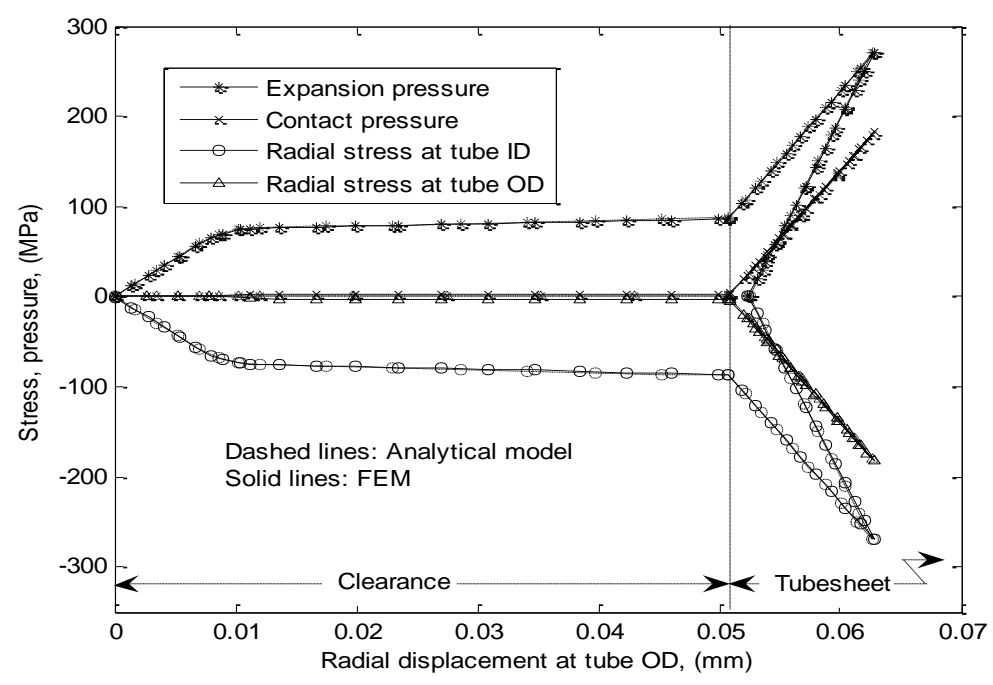

Fig. 4 Stress variations during expansion:

Case of expansion without tubesheet plastic deformation

end of the expansion process, the predicted residual contact stress is $28.8 \mathrm{MPa}$ versus $27.3 \mathrm{MPa}$ with FEA while Eq. (1) gives 20.6 MPa. The percentage difference with respect to FEM is 5\% for the analytical model while it is $25 \%$ with Eq.(1). It is to be noted that Eq. (12) is valid for both cases of tubesheet elastic and plastic states but without reverse yielding of the tube. The reason behind the major difference between Allam's model and the analytical model presented in this paper is that the compatibility of the displacement during the unloading is not taken into consideration in the former model. The residual contact pressure is plotted versus the initial clearance in Fig. 6 for several values of tangent modulus. The ranges of these parameters were selected so as to cover most of industrial applications. Referring to this graph, the residual contact pressure decreases with an increase in the tube tangent modulus with a quasi linear relationship if the tubesheet remains elastic. Obviously, there is no effect of initial clearance when $\mathrm{E}_{\mathrm{tt}}$ tends towards zero which represents the elastic perfectly plastic behaviour, confirmed by Merah N. et al., 2003. Figure 7 shows the effect of strain hardening in the case where partial yielding of the tubesheet is present. It can be seen that a relationship between the residual contact pressure and the tangent modulus is practically linear. It is to be noted that the strain hardening of the tubesheet has little effect on the residual contact stress. The slight difference between the analytical FEM results is beleaved to be due to the penetration tolerance that is used by the FEM software to assume there is contact between the tube and the tubesheet in addition to the plastic Poisson's ratio that cannot be used exactly equal to 0.5 in FEM softwares as Lamé constant $\lambda$ becomes infinity.

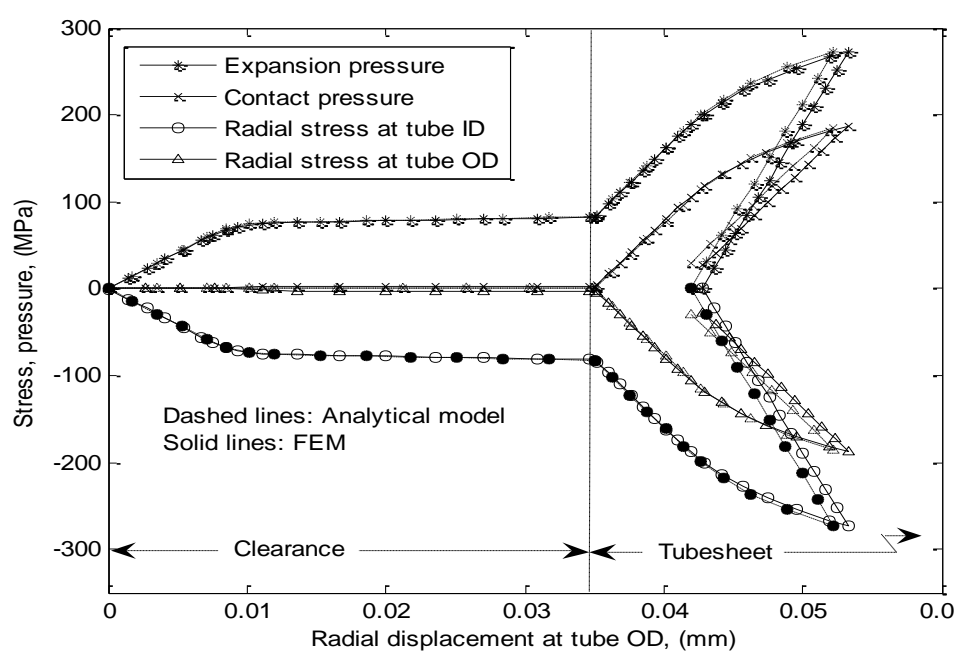

Fig. 5 Stress variations during expansion:

Case of expansion with tubesheet plastic deformation 


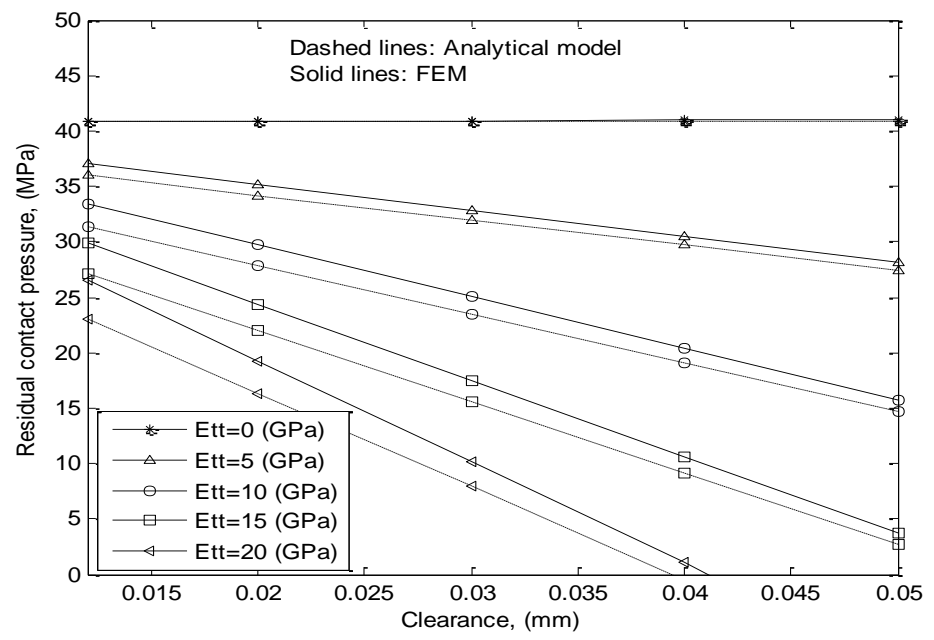

Fig. 6 Residual contact pressure variation with initial clearance

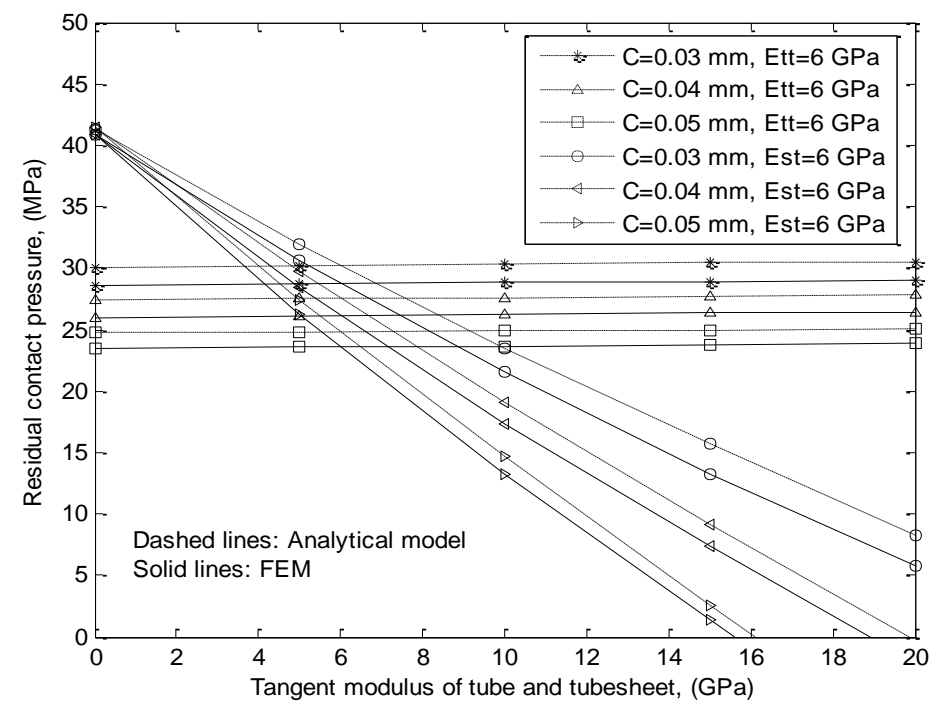

Fig. 7 Residual contact pressure variation with tube and tubesheet

\section{Analytical modeling of creep relaxation}

Steam generators are the subject of major concern in nuclear power plant safety. Within these generators, the tightness barrier, which separates the primary and secondary circuits, is ensured by the existence of a residual contact pressure at the tube-to-tubesheet joint interface. Any leakage is unacceptable, and its consequences are very heavy in terms of the human and environmental safety as well as maintenance cost. Some studies have been conducted to comprehend the main reasons for such failure. However, there is no analytical model able to predict the attenuation of the residual contact pressure under the effect of material creep relaxation behavior. The development of a simple analytical model able to predict the change of the residual contact pressure as a function of time is presented. The results from the analytical model are checked and compared to those obtained by finite elements.

\subsection{Governing equations}

The equation governing the tube-to-tubesheet joint equilibrium considered as thick cylinders is given by:

$$
\frac{d \sigma_{r}^{i}}{d r}+\frac{\sigma_{r}^{i}-\sigma_{\theta}^{i}}{r}=0
$$


Total strains are assumed to be composed of three parts; elastic, thermal and creep strain.

$$
\varepsilon^{i}=\varepsilon_{e l}^{i}+\varepsilon_{t h}^{i}+\varepsilon_{c r}^{i}
$$

The elastic $\varepsilon_{e l}^{i}$ and thermal $\varepsilon_{t h}^{i}$ strains may be obtained from Hooke's law with thermal expansion or contraction, respectively. Creep strain components $\varepsilon_{c r}^{i}$ are assumed to follow Norton's law (Bailey, 1935).

$$
\varepsilon_{c r}^{i}=K_{i} \cdot\left(\sigma_{e}^{i}\right)^{n_{i}} \cdot t
$$

$K_{i}$ and $n_{i}$, are creep constants, $\sigma_{e}{ }^{\prime}$ and $t$ are the Von Mises effective stress and time parameter, respectively. The radial and tangential stresses $\sigma_{r}^{i}$ and $\sigma_{\theta}^{i}$ are then given by:

$$
\begin{gathered}
\sigma_{r}^{i}=\frac{E_{i}}{1-v_{i}^{2}}\left[\frac{d U_{r}^{i}}{d r}+v \frac{U_{r}^{i}}{r}-\left(\varepsilon_{r, c r}+v \varepsilon_{\theta, c r}\right)-\left(1+v_{i}\right) \alpha_{i} \Delta T\right] \\
\sigma_{\theta}^{i}=\frac{E_{i}}{1-v_{i}^{2}}\left[v \frac{d U_{r}^{i}}{d r}+\frac{U_{r}^{i}}{r}-\left(v \varepsilon_{r, c r}+\varepsilon_{\theta, c r}\right)-\left(1+v_{i}\right) \alpha_{i} \Delta T\right]
\end{gathered}
$$

Substituting (20) into Eq. (17) gives:

$$
\begin{array}{ll}
\frac{d^{2} \dot{U}_{r}^{i}}{d r^{2}}+\frac{1}{r} \frac{d \dot{U}_{r}^{i}}{d r}-\frac{1}{r^{2}} \dot{U}_{r}^{i}=0 & t=0 \\
\frac{d^{2} \dot{U}_{r}^{i}}{d r^{2}}+\frac{1}{r} \frac{d \dot{U}_{r}^{i}}{d r}-\frac{1}{r^{2}} \dot{U}_{r}^{i}=\frac{\dot{g}_{1}^{i}}{r}+\frac{d \dot{g}_{2}^{i}}{d r} & t>0
\end{array}
$$

The general solution of Eq. (21) is:

$$
\dot{U}_{r}^{i}=A_{i} r+\frac{B_{i}}{r}-\left(\frac{I_{1}^{i}}{1-v}+\frac{I_{2}^{i}}{1+v}\right) r
$$

$A_{i}$ and $B_{i}$ are the integration constants to be found by applying the boundary conditions. $I_{1}^{i}$ and $I_{2}^{i}$ are by:

$$
\begin{aligned}
& I_{1}^{i}=\frac{1-v}{2 r^{2}} \int_{r_{i}}^{r}\left(\dot{g}_{1}^{i}-2 \dot{g}_{2}^{i}\right) r d r \\
& I_{2}^{i}=\frac{1+v}{2} \int_{r_{i}}^{r} \frac{\dot{g}_{1}^{i}}{r} d r
\end{aligned}
$$

Where:

$$
\begin{aligned}
& \dot{g}_{1}^{i}=(1-v)\left(\dot{\varepsilon}_{r, c r}^{i}-\dot{\varepsilon}_{\theta, c r}^{i}\right) \\
& \dot{g}_{2}^{i}=\left(\dot{\varepsilon}_{r, c r}^{i}+\dot{\varepsilon}_{\theta, c r}^{i}\right)
\end{aligned}
$$

The stress rates are given by:

$$
\begin{aligned}
& \dot{\sigma}_{r}^{i}=\frac{E_{i}}{1-v^{2}}\left[A_{i}(1+v)-B_{i} \frac{(1-v)}{r^{2}}+I_{1}^{i}+I_{2}^{i}\right] \\
& \dot{\sigma}_{\theta}^{i}=\frac{E_{i}}{1-v^{2}}\left[A_{i}(1+v)+B_{i} \frac{(1-v)}{r^{2}}-I_{1}^{i}+I_{2}^{i}-\left(1-v^{2}\right) \dot{\varepsilon}_{\theta, c r}^{i}\right]
\end{aligned}
$$

The radial and tangential strain rates are given by the Prandtl Reuss flow rule (Nabarro, 1948) as follows:

$$
\begin{aligned}
& \dot{\varepsilon}_{r, c r}^{i}=K_{i}\left(\sigma_{e}^{i}\right)^{n_{i}-1}\left(\sigma_{r}^{i}-\sigma_{\theta}^{i}\right) \\
& \dot{\varepsilon}_{\theta, c r}^{i}=K_{i}\left(\sigma_{e}^{i}\right)^{n_{i}-1}\left(\sigma_{\theta}^{i}-\sigma_{r}^{i}\right)
\end{aligned}
$$




\subsection{Summary of computational procedure}

Step 1: The initial stresses at $\mathrm{t}=0$ are given by Lames equations

Step 2: Use the stresses from step 1 to calculate the strain rates

Step 3: Applying the boundary conditions the constants $\mathrm{A}_{\mathrm{i}}$ and $\mathrm{B}_{\mathrm{i}}$ are solved to obtain the stress rates.

Step 4: By selecting a suitable time interval $\Delta \mathrm{t}$, the new stresses and strains can be found:

$$
\begin{aligned}
& \left(\sigma_{r}^{i}\right)_{j+1}=\left(\dot{\sigma}_{r}^{i}\right)_{j} \Delta t+\left(\sigma_{r}^{i}\right)_{j} ; \\
& \left(\sigma_{\theta}^{i}\right)_{j+1}=\left(\dot{\sigma}_{\theta}^{i}\right)_{j} \Delta t+\left(\sigma_{\theta}^{i}\right)_{j} \\
& \left(\varepsilon_{r}^{i}\right)_{j+1}=\left(\dot{\varepsilon}_{r}^{i}\right)_{j} \Delta t+\left(\varepsilon_{r}^{i}\right)_{j} \\
& \left(\varepsilon_{\theta}^{i}\right)_{j+1}=\left(\dot{\varepsilon}_{\theta}^{i}\right)_{j} \Delta t+\left(\varepsilon_{\theta}^{i}\right)_{j}
\end{aligned}
$$

\begin{tabular}{|c|c|c|}
\hline & Tube & Tubesheet \\
\hline$r_{o}, R_{o} \quad[\mathrm{~mm}]$ & 9.512 & 36 \\
\hline$r_{i}, R_{i} \quad[\mathrm{~mm}]$ & 7.272 & 9.547 \\
\hline$E_{t}, E_{s} \quad[\mathrm{GPa}]$ & 196 & 218 \\
\hline$E_{t t}, E_{t s}[\mathrm{GPa}]$ & 3 & 2 \\
\hline$S_{y t}, S_{y s}[\mathrm{MPa}]$ & 329 & 415 \\
\hline$K_{t}\left[\mathrm{MPa}^{-\mathrm{n}_{t}} \mathrm{~h}^{-1}\right], K_{s}\left[\mathrm{MPa}^{-\mathrm{n}_{s}} \mathrm{~h}^{-1}\right]$ & $1.4610^{-26}$ & $1.110^{-22}$ \\
\hline$n_{t}, n_{s}$ & 10.64 & 8.25 \\
\hline$v_{t}, v_{s}$ & 0.3 & 0.3 \\
\hline$\alpha_{t}, \alpha_{s}\left[\mu \mathrm{s}^{\circ} \mathrm{C}^{-1}\right]$ & 13.01 & 12.4 \\
\hline$P_{e_{-} \max }[\mathrm{MPa}]$ & \multicolumn{2}{|c|}{340} \\
\hline$P_{d}[\mathrm{MPa}]$ & \multicolumn{2}{|c|}{16} \\
\hline$C[\mathrm{~mm}]$ & \multicolumn{2}{|c|}{0.035} \\
\hline$\Delta T\left[{ }^{\circ} \mathrm{C}\right]$ & \multicolumn{2}{|c|}{550} \\
\hline
\end{tabular}

Step 5: Step 2 to 4 are repeated for each time interval until the radial and tangential stress distribution reach a steady state condition.

Table 2 Geometry and material properties

\subsection{Results and analysis of creep-relaxation}

The geometrical characteristics of the tube-to-tubesheet joint selected for the validation study are shown in Table 2. The material properties including creep constants for alloy 800 (El Gharad, 1986) and ASTM SA 387 (Gaffard, 2004) are also given in Table 2. As shown in this table, in the working example, the loading conditions of pressure and temperature are taken from the primary side circuit only. The secondary side circuit pressure is neglected since this paper does not deal with the tube transition zone. The developed analytical approach was validated using both plane stress and axisymmetric FE modelling. Isoparametric plane elements with eight nodes were used to model the tube and the tubesheet. Figure 8 shows the residual radial stress distribution immediately after the expansion process with no pressure and temperature applied. The analytical model predicts a contact pressure of $25.6 \mathrm{MPa}$ while FEA gives 29.3 and 28.8 MPa for plane stress and axisymmetric models representing a difference of 12 and $11 \%$ respectively.

Figure 9 shows the radial stress distribution at a pressure of $16 \mathrm{MPa}$ a temperature increase of $550^{\circ} \mathrm{C}$ and after 10000 hours of service. The analytical prediction of both stresses is in a perfect match with FEA and in particular with the FE plane stress model. The analytical model predicts a contact pressure of $23.59 \mathrm{MPa}$ while FEA gives 23.4 and 22.9 MPa representing a difference of 1 and 3\% respectively, for the plane stress and axisymmetric models. 


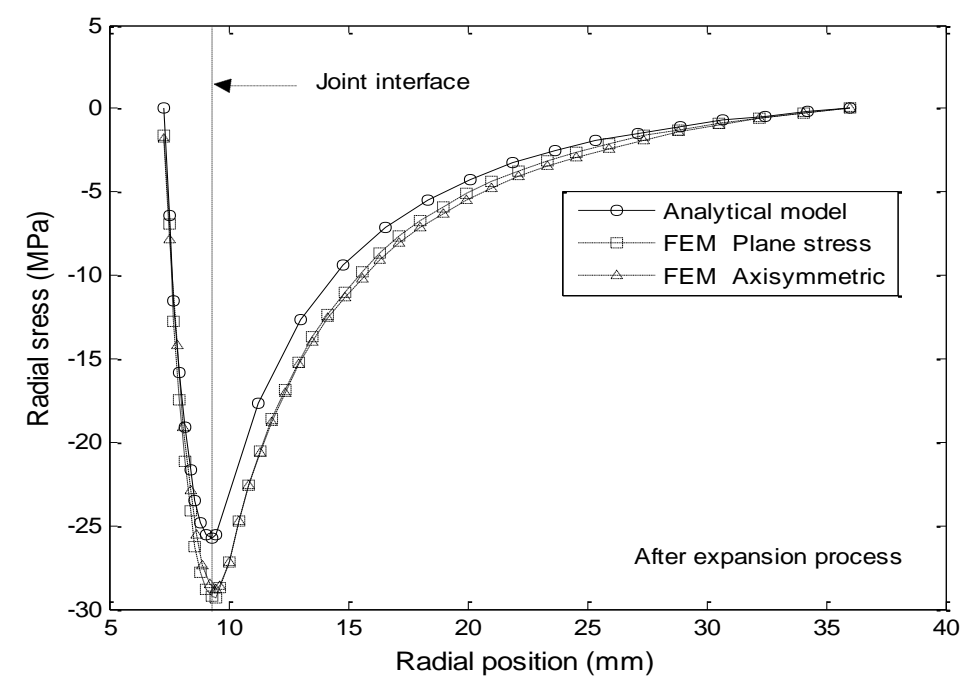

Fig. 8 Radial stress distribution after the expansion process

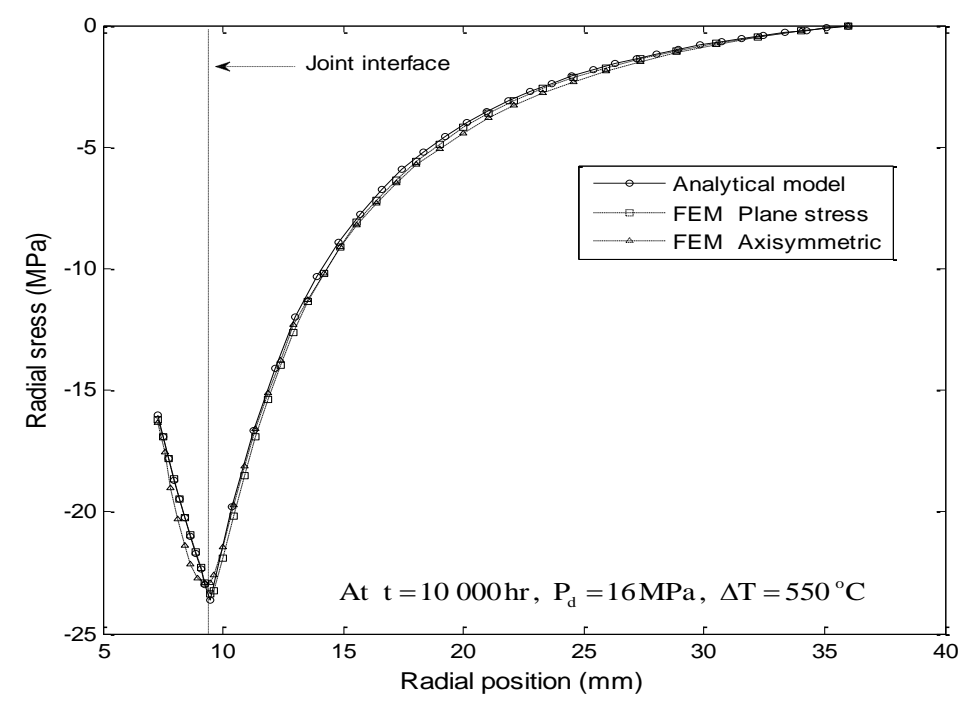

Fig. 9 Radial stress distribution at the steady state condition

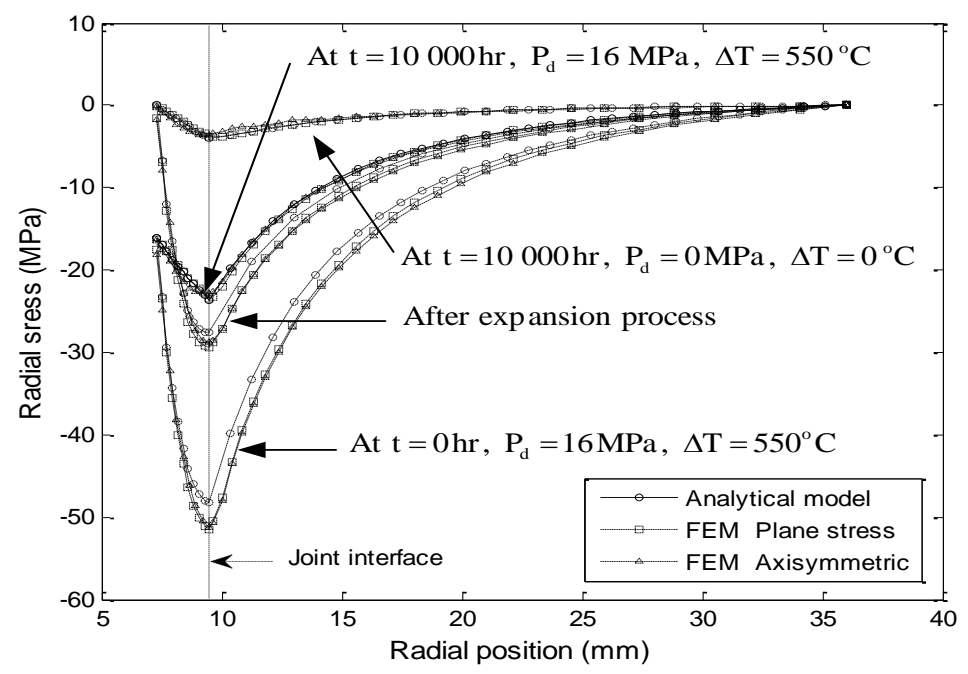

Fig. 10 Radial stress distributions during the different operating conditions 
Figure 10 shows the stress distribution in service at different operating stages. The residual contact pressure, initially at 25.58 $\mathrm{MPa}$ after the expansion process, reaches to around 48.28 $\mathrm{MPa}$ during operation the first few hours and then decreases to $23.59 \mathrm{MPa}$ after 10,000 hours of service $\left(\mathrm{P}_{\mathrm{d}}=16 \mathrm{MPa}\right.$ and $\left.\Delta \mathrm{T}=550^{\circ} \mathrm{C}\right)$ resulting in a reduction of $51.2 \%$. The FE models predict a reduction of 54,25 and $55.3 \%$ for the FE plane stress and axisymmetric models representing a difference of 5 and $7 \%$, respectively. The state of the contact pressure is critical during shut-down since its value is less than 4.4 MPa as shown in Fig. 11 under the condition $\left(\mathrm{P}_{\mathrm{d}}=0 \mathrm{MPa}\right.$ and $\Delta \mathrm{T}=0^{\circ} \mathrm{C}$ and $\mathrm{t}=10000$ hours $)$. This represents a reduction of $83.9 \%$ for analytical model against 87.5 and $86.4 \%$ for the FE plane stress and axisymmetric models giving a difference of 4 and $3 \%$ respectively.

The joint relieves stresses considerably during operation. Indeed, in the analytical model, the maximum absolute value of the effective stress at tube inner radius increases slightly from $231.9 \mathrm{MPa}$ to $280.6 \mathrm{MPa}$ during operation and then decrease drastically to $48.4 \mathrm{MPa}$ after 10,000 hours of service. Similar behavior is observed with the two FE models. Figure 11 shows the variation of residual contact pressure with time. After the tube-to-tubesheet joint is brought into service, the residual contact pressure increases from 27.9 to $50.32 \mathrm{MPa}$ due to internal pressure and thermal expansion difference.

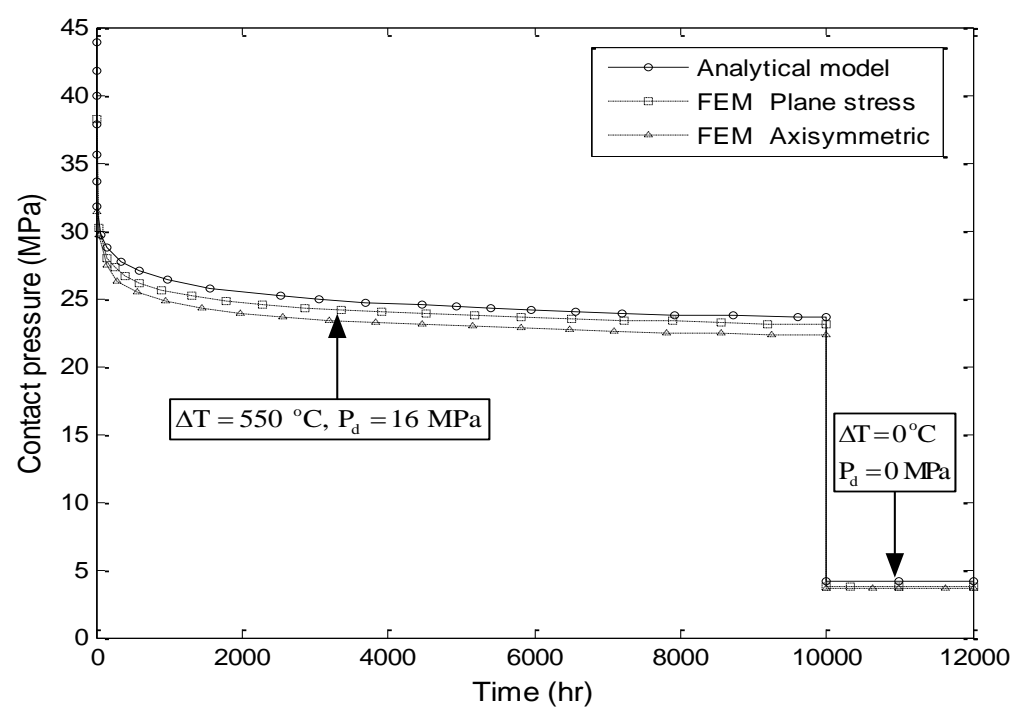

Fig. 11 Contact pressure relaxation with time

\section{Conclusion}

An accurate analytical model that treats tube-to-tubesheet joint hydraulic expansion and relaxation was developed in this paper. It takes into account not only the strain hardening effect on the initial residual stresses generated during the expansion process as well as the effect of pressure, thermal expansion difference and creep. The developed analytical model was validated against FEA and was found to give a good estimate of the contact pressure and the stresses in the joint at both service condition and cold shutdown. The maximum difference between the analytical model and FEA is $12 \%$ which strengthen the credibility of the developed model. The main following points are to be retained. Both tube strain hardening and clearance have significant effect on the residual contact pressure. The increase of these two parameters produces a linear decrease in contact pressure. The strain hardening of tubesheet has little effect on the residual contact pressure. If the tube tangent modulus approaches zero, the initial clearance effect on the residual contact pressure is not significant. While the contact pressure increases immediately after application of pressure and temperature, it can decrease to a much lower value after few hours of service and in particular when the loading is retrieved. At the steady state condition, the residual contact pressure decrease by $16.5 \%$ and $86 \%$ with respect to the initial residual contact pressure obtained at the end of the expansion process. 


\section{Notation}

\begin{tabular}{|c|c|}
\hline$\alpha_{t}, \alpha_{s}$ & Thermal expansion coefficient of tube and tubesheet, ${ }^{\circ} \mathrm{C}^{-1}$ \\
\hline$\varepsilon_{e l}^{i}, \dot{\varepsilon}_{t h,}^{i} \dot{\varepsilon}_{c r}^{i}$ & Total elastic, thermal and creep strains \\
\hline$\varepsilon_{r}^{i}, \varepsilon \theta^{i}$ & Total radial and tangential strain \\
\hline$\varepsilon_{r, c r}^{i}, \varepsilon \theta^{\dot{j}}, c r$ & Radial and tangential creep strain \\
\hline$\dot{\varepsilon_{r}, c r}, \dot{\varepsilon} \dot{\theta}, c r$ & Rate of radial and tangential creep strain, $\left(\mathrm{h}^{-1}\right)$ \\
\hline$v_{t}, v_{s}$ & Poisson ratio of tube and tubesheet \\
\hline $\bar{v}$ & Plastic Poisson ratio $=0.5$ \\
\hline$\sigma_{e}^{i}$ & Von Mises effective stress, (MPa) \\
\hline$\sigma_{r}^{i}, \sigma^{j}$ & Radial and tangential stress, $(\mathrm{MPa})$ \\
\hline$\dot{\sigma}_{r}^{i}, \dot{\sigma \theta}^{j}$ & Rate of radial and tangential stress, $(\mathrm{MPa} / \mathrm{h})$ \\
\hline$C$ & Initial clearance, $(\mathrm{mm})$ \\
\hline$E_{t}, E_{s}$ & Elastic moduli of tube and tubesheet, $(\mathrm{MPa})$ \\
\hline$E_{p t}, E_{t t}$ & Tube plastic and Tangent moduli, (MPa) \\
\hline$E_{p s}, E_{t s}$ & Tubesheet plastic and tangent moduli, $(\mathrm{MPa})$ \\
\hline$K_{i}$ & Creep constants for Norton's law \\
\hline$n_{i}$ & Material constants for Norton's law \\
\hline$P_{e}, P_{e \_ \text {max }}, P_{e \_ \text {min }}$ & Expansion pressure and its maximum minimum values, (MPa) \\
\hline$P_{\text {esys }}$ & Expansion pressure to start yield in tubesheet, $(\mathrm{MPa})$ \\
\hline$P_{d}$ & Operating pressure, $(\mathrm{MPa})$ \\
\hline$P_{c}, P_{c_{-} \max }$ & Contact pressure during expansion and its maximum value, $(\mathrm{MPa})$ \\
\hline$P_{a t}, P_{a s}$ & Autofrettaged pressure of tube and tubesheet, $(\mathrm{MPa})$ \\
\hline$r$ & Radius, (mm) \\
\hline$r_{i}, r_{o}$ & Inner and outer tube radii, $(\mathrm{mm})$ \\
\hline$R_{i}, R_{o}$ & Inner and outer tubesheet radii, $(\mathrm{mm})$ \\
\hline$S_{y t}, S_{y s}$ & Yield stress of tube and tubesheet, $(\mathrm{MPa})$ \\
\hline$U_{r}^{i}$ & Radial displacement, (mm) \\
\hline$\dot{U}_{r}^{i}$ & Rate of radial displacement, $\left(\mathrm{mm} / \mathrm{h}^{-1}\right)$ \\
\hline$Y_{t}, Y_{s}$ & Ratio of outside to inside radii of tube and tubesheet \\
\hline$t$ & Time, (h) \\
\hline$\Delta t$ & Time interval, (h) \\
\hline$\Delta T$ & Temperature, $\left({ }^{\circ} \mathrm{C}\right)$ \\
\hline$Y_{i}$ & Inner to outer diameter ratio \\
\hline
\end{tabular}

\section{Subscript and supercript}

$\begin{array}{ll}i & \text { refers to either tube or tubesheet } \\ s & \text { refers to tubesheet } \\ t & \text { refers to tube }\end{array}$

\section{Acronyms}

FEA Finite Element Analysis

ID Inside diameter

OD Outside diameter

\section{References}

Allam M. and Bazergui, A., Axial strength of tube-to-tubesheet joints: Finite element and experimental evaluations, Journal of Pressure Vessel Technology, Vol.124, No.1 (2002), pp. 22-31.

Allam, M., Chaaban, A. and Bazergui, A., Estimation of residual stresses in hydraulically expanded tube-to-tubesheet joints, Journal of Pressure Vessel Technology, Vol.120 (1998), pp 129-137. 
Bailey R.W., The Utilization of Creep Test Data in Engineering Design, Proc IMechE, Vol.131 (1935), pp. 186-205.

Chaaban, A., Ma, H. and Bazergui, A., Tube-Tubesheet Joint: A Proposed Equation for the Equivalent Sleeve Diameter Used in the Single Tube Model, ASME Journal of Pressure Vessel Technology, Vol.114, No.1 (1992), pp. 19-22.

Cizelj, L. and Mavko, B., Crack propagation in residual stress dominated steam generator tube expansion transition zones, Proc. of the Meeting on Nuclear Energy: Central Europe: Present and Perspectives (1993), pp. 228-235.

EL Gharad, A., Comportement en Fatigue Relaxation de l'Alliage 800 (Z 5 NCT A 33-21) à 550 ${ }^{\circ}$. Influence du Vieillissement et Prévision à Long Terme, Ph.D thesis (1986), Metz University.

Gaffard, V., Experimental Study and Modelling of High Temperature Creep Flow and Damage Behaviour of 9Cr1Mo-Nbv Steel Weldments, Ph.D Thesis (2004), Ecole des Mines de Paris

Goodier, J. N., and Schoessow, G. J., The Holding Power and Hydraulic Tightness of Expanded Tube Joints: Analysis of the Stress and Deformation, Transaction of ASME, Vol.65, No.5 (1943), pp. 489-496.

Grimison, E.D. and Lee, G.H., Experimental Investigation of Tube Expanding, Transaction of ASME, Vol.65, No.5 (1943), pp. 497-505.

Kohlpaintner, W.R., Calculation of hydraulically expanded tube-to-tubesheet joints, ASME Journal of Pressure Vessel Technology, Vol.117 (1995), pp. 24-30.

Krips, H., and Podhorsky, M., Hydraulisches Aufweiten Em Dash Ein Neues Verfahren Zur Befestigung Von Rohren, VGB Kraftwerkstechnik, Vol.56, No.7 (1976), pp. 456-464.

Laghzale N. and Bouzid A., Analytical Modelling of Hydraulically Expanded Tube-To-Tubesheet Joints, ASME Journal of Pressure Vessel Technology, Vol.131, No.1 (2009a), 011208

Laghzale N. and Bouzid A., "Theoretical Analysis of Hydraulically Expanded Tube-To-Tubesheet Joints with Linear Strain Hardening Material Behavior," ASME Journal of Pressure Vessel Technolog, 131, No.6 (2009b), 061202-8

Livieri, P. and Lazzarin, P., "Different solutions for stress and strain fields in autofrettaged thick-walled cylinders," International Journal of Pressure Vessels and Piping, 71 (1997), pp. 231-238

Merah, N., Al-Zayer, A., Shuaib, A. and Arif, A., Finite element evaluation of clearance effect on tube-to-tubesheet joint strength, International Journal of Pressure Vessel and Piping, Vol.80, No.12 (2003), pp. 879-885.

Middlebrooks W.B., Harrod D.L. and Gold R.E., Residual stresses associated with the hydraulic expansion of steam generator tubing into tubesheet, Nuclear Engineering and Design, Vol.143 No.2-3 (1993), pp. 159-169

Nabarro F.R.N., Report of a conference on the strength of solids, London: Physical Society, (1948).

Ramberg, W., and Osgood, W. T., Description of stress-strain curves by three parameters, National Advisory Committee for Aeronautics, Technical Notes, n 902, Washington, D.C., (1943). 13p.

Sang Z. F., Zhu Y. Z. and Widera G. E. O., Reliability factors and tightness of tube-to-tubesheet joints, ASME Journal of Pressure Vessel Technology, Vol.118 (1996), pp.137-41.

Shuaib A.N., Merah N. and Allam I., Investigation of heat exchanger tube sheet hole enlargement, ME2203 Final Report (2001), King Fahd University of Petroleum, Dhahran, Saudi Arabia.

TEMA, Standards of the Tubular Exchanger Manufacturers Association, Tarrytown, New York, (1999), 8th ed, the Tubular Manufacturers Association.

Yokell, S., Expanded, and Welded-and-Expanded Tube-to-Tubesheet Joints, ASME Journal of Pressure Vessel Technology, Vol.114 (1992), pp. 157-165. 